\title{
Competitive pressures and engineering \\ process plant contracting
}

Ian Clark, School of Business, De Montfort University

$\mathrm{T}$

his article reports on a case study of a leading project management firm in engineering process plant contracting (EPPC), an internationalised industry that is largely unresearched by HR specialists. The study examines how one such company, 'Exbeck', has responded to external competitive pressures through a process of internal restructuring. ${ }^{1}$ Exbeck made its corporate HR function a full business partner in project management, a controversial and risky move that recognised the strategic potential of the function. In this role the function assumed executive control of management development and, more controversially, began monitoring corporate and divisional performance within project pre-planning and operations.

The study was conducted over a five-year period between 1990 and 1995, with repeat interviews, participation in and observation of emergent organisational responses - in particular senior management conferences, strategy and operational meetings and briefings on the repositioning of the HR function. Numerous structured interviews were conducted and complemented by access to all Exbeck's internal documents on its 'Human resources agent for change' programme. The research methods that were employed - types and numbers of people interviewed, method of interview and nature of data capture and analysis - are discussed in Appendix 1.

The contribution of this study to practitioner and academic knowledge and debate is threefold. First, it presents details of a rare attempt to make the HR function more strategic. Secondly, this attempt is particularly interesting because, contrary to popular images of HRM, it involves removing unilateral control from line managers by positioning the corporate HR function in a 'producer' role in project management, ie centralising executive responsibility for human resources rather than devolving it to line management. Thirdly, the organisation has made a serious attempt to measure the impact of the changes on its financial performance; this is interesting in that the impact of the repositioning of human resources was measured in terms of 'cost containment' rather than 'cost reduction'. The article presents and discusses data on these issues and concludes by discussing the wider implications of its findings.

\section{COMPETITIVE FRAMEWORK AND CONDITIONS}

The EPPC industry consists of about 100 firms worldwide whose primary business function is to design, construct, procure and test investment projects for process producers. Process producers operate in a variety of sectors: oil and gas (oil and gas refineries), chemical production (eg eythelene or plastics), steel production (steel works), and the construction of gas, oil or coal-powered electricity generating stations. In addition, contractors work on unique engineering projects such as bridge construction, the Channel tunnel or extensions to underground railway systems. Lastly, some EPPC firms work on nuclear power stations, regenerating stations or storage plants. 
The majority of the firms in the industry are multinationals, and work on projects is undertaken worldwide. Capital projects, oil refineries or chemical plants are initiated by producer firms - oil companies or chemical producers - through a process of project tenders. A producer firm may advertise in the trade press ${ }^{2}$ or approach a number of project management firms and invite tenders. Many projects are so large that project management firms organise consortia bids or initiate particular joint ventures (see Clark and Ball, 1991). Process producers prefer to offer tenders for 'lump sum turnkey' contracts, where the price is specified for hardware, process technology and labour. The price may be 'fixed' or, alternatively, it may be subject to variation by an agreed formula for changes in the rate for materials or labour.

Within EPPC there are three distinct types of firm: constructors, the best of which are Japanese firms (Ball, 1985); process technology license holders, ie monopoly sources of specific chemical or other technological processes, the majority of which are German or British (Ball, 1985); and project managers such as Exbeck. In 1992 Exbeck employed 21,000 administrative, clerical and technical staff and 10,000 craft workers including engineers, project managers, specialist process engineers, chemists and physicists. The value of work performed in 1991 was $\$ 7.5$ billion. The average cost of an Exbeck project is $\$ 85$ million, but some super projects can reach the order of $\$ 300$ million. In capacity terms steam generators for nuclear power stations can weigh up to 460 tons whereas aluminium smelters can have a capacity of 200,000 tons per year.

Project managers design projects, select constructors, procure the necessary technologies and arrange and manage finance. They sell their technical expertise and person hours to the client, oversee construction and process testing and manage, monitor and oversee the entire project. In particular the project manager formulates the legal relationship between themselves, process technologists, constructors and the client.

The dangers of competitive failure and the presence of monopoly technology holders preclude the use of large scale subcontracting, hence within consortia, joint venture or single firm projects the opportunities for externalisation to cut labour and materials costs are limited. Equally, patent specifications, statutory testing requirements and standards for tube and valve pressures make it impossible for constructors to subcontract for materials production on the basis of cost. Where firms do use subcontractors, it is usual for constructors, technology holders or project managers to build up 'partnering' arrangements. These are strategic alliances between EPPC firms, constructors and site subcontractors that guarantee an annual workload in return for 'ranged prices' for the work (see Ball et al, 1992) The constructor or project manager knows the quality of the work is guaranteed within a range of tender prices. The benefits of this type of relationship are that the formulation of tenders is more certain and the process builds up trust between interdependent firms. However, the relationships still operate on the basis of a turnkey contract. And, as Clark and Ball (1991) demonstrate, the opportunities for cost minimisation through direct subcontracting are limited. But the use of consortia, joint ventures and partnering arrangements do afford project managers opportunities to pass on potential costs to consortia or joint venture partners by bringing de facto subcontractors into projects as full partners.

Contemporary competitive conditions have tightened for four reasons. First, the market price of oil has fallen considerably. As a consequence there is less oil refinery business and, in addition, on current projects the mark-up for project managers' profits has been severely tightened. In the early 1980s the mark up was in the region of 20 per cent, whereas in 1995 it stood at around 10 per cent. Secondly, industrial recession in western Europe has reduced new orders for chemicals and steel plants. Recession led to the reduction of existing capacity and similar reductions in mark-up capacities for project managers. Thirdly, the unification of 
Germany and the collapse of the eastern bloc has changed the nature of business. Contractors are now in the business of bidding for clean-up work to make previously unregulated chemical plants more environmentally friendly; equally, the availability of 'new capacity' in eastern Germany has further reduced the demand for new starts in western Germany. Lastly, environmental disasters such as those at Harrisburg, Chernobyl and Bhopal have sharpened contractors' awareness of potential legal liability.

Prior to 1992 Exbeck's business strategy revolved around an internal power balance that saw engineers and project managers as the central actors or 'kingpins'. As Exbeck approached the contemporary period, the central role of kingpins became problematic. In particular budget overruns on projects often centred on HR issues that kingpins did not recognise as significant. Interviews and questionnaires carried out as part of this project confirmed the findings of an Exbeck attitude survey which indicated that employees felt the management-by-objectives structure in independent project management was breaking down. In addition, many senior project managers and engineers who were interviewed indicated that, during this period, corporate business managers and the marketing and procurement department were bidding for and winning business which they did not want, therefore overstretching the engineering and design functions.

It appeared that Exbeck was running its operations as if boom conditions existed, whereas competitive conditions and mark-ups were getting tighter. By late 1991 the executive board decided that the situation was not sustainable; cash flow was a major problem due to budget overruns and staff appraisals indicated widespread dismay at engineer, project manager and site manager levels and huge frustration in HRM:

They blame us all the while, but we have no idea what level and type of contracts they are committing staff to. A typical response to us telling them there are no process design engineers available is 'well, go run a fire drill then and find one!'

Exbeck compromised on its human resources through a process of project ranking: 'hot projects' could appropriate engineers, design staff and project managers from 'cold projects' at short notice. As the subsequent internal business review illustrated, the overall effect of this was the implicit acceptance of cost overruns on some projects. Equally, the management and deployment of human resources was completely reactive. Exbeck's executive board recognised that the HR function was currently what Purcell and Alhstrand (1994) term a 'functional third order priority', operating downstream from decisions on the long-term direction of the firm and its internal operating procedures. The latter represents first and second order levels of decision making, both of which have an upward influence on strategy. In Exbeck the peripheral role of human resources manifested itself as responding to the unilateral demands of project managers and maintaining personnel and employee relations systems. In an effort to address this situation a wide-ranging business review was undertaken that resulted in the current business and HR strategies.

\section{COMPETITIVE STRATEGY}

\section{Business review and human resources}

As a response to the crises of cash flow and cost overruns the board of directors initiated the internal business review in conjunction with a well-known management consulting firm; five interim findings were presented by the chief executive at Exbeck's US corporate headquarters. The dissemination of the findings was presented in a two-day review conference at which the author was present. 
First, it was made perfectly clear that the decline in project management work and project management mark-ups were not temporary set-backs, as in the case of the 1972-1974 and 1979-1981 recessions.

Secondly, it was argued that Exbeck had to be more selective over its bidding because, while projects were becoming fewer, they were getting much larger, and therefore better project forecasting and work execution excellence was necessary. That is, there was no point in bidding for and winning work if it could not be resourced without budget overruns; margins were smaller and eating into them was eroding profitability. As Exbeck sells human resources as turnkey hours, either on design and procurement or on site in project management, the situation was no longer sustainable.

Thirdly, the labour intensive nature of EPPC precluded downsizing engineering and project management staff in an effort to cut labour costs other than on the margin. Fourthly, the Exbeck president reluctantly argued that it was essential for the HR function to be reorganised and repositioned in project management as a 'producer' rather than in its current 'go for' role. That is, at corporate level the function had to be made a full business partner in project management. In subsequent interviews with the president it was established that his reluctance was not because he did not believe in the promotion of the HR function; rather, he knew that such an initiative would seriously challenge the existing hierarchy of staffing, ie the kingpin profile of engineers and project managers.

Lastly, for clerical and administrative staff at corporate and divisional levels it was felt necessary to introduce a 'new deal' because these staff had borne the brunt of much of the confusion in business planning over the last three years. In consequence staff turnover was running unacceptably high, whereas staff appraisals and employee attitude surveys indicated that staff morale, trust and motivation were running at unacceptably low levels.

The Exbeck board was unconvinced by the HRM rhetoric and immediate (transformation) action plan presented to them by the commissioned management consultants. The head of human resources referred to much of the American academic and consultant-based work on HRM as 'designer HRM', arguing that it represented an 'American tale' of good over bad. These views bear out British-based critiques of the American model (Guest, 1990 and Legge's review of the 'American dream', 1995: 85-87).

In essence, Exbeck wanted to harness its human resources more effectively in order to maintain its competitive position within a tighter competitive environment. In contrast, the consultants formulated a programme that was designed to raise Exbeck's competitive profile, which the board felt to be inappropriate. It was argued that attempts to raise Exbeck's competitive standing would add to their present difficulties. In consequence any attempt to raise the competitive profile was seen as misguided in the absence of rooting out organisational failures in the firm's business procedures.

The board rejected the consultants' recommendations and devised its own programme of internal restructuring and management development. The aim of this was to contain operational costs to levels that Exbeck had indicated it could meet in project pre-planning and tender bids to process producers. The corporate HR function was identified as a potentially significant player in this process. The specific details of the business and HR strategies are now outlined.

\section{Internal restructuring and management development}

In order to address the tighter competitive environment, Exbeck introduced two innovations at corporate level. First, it identified four cornerstones to its competitive strategy: management development, technical excellence, work execution excellence and marketing 
and business planning excellence. Secondly, Exbeck streamlined its divisional structure into five coherent divisions: legal and public relations, construction and contracts, human resources, process and technological research and the European division controlling petroleum and industrial chemicals production. Each division has an 'executive sponsor' who is a member of the Exbeck executive board. The most significant aspect of these innovations was that human resources became a division in its own right, whereas previously it had been an operational unit responding to the resource and development needs of line management. Executive sponsors are responsible for managing their particular division but also have a brief to drive and steer one cornerstone of Exbeck's competitive strategy (see Figure 1).

The primary object of these innovations was to reform the management structure and improve the internal delivery and resourcing of contracts. The introduction of these developments was not seen as an internal transformation but more significantly as a response to external competitive conditions. For example, 'ownership' of staff remained a line function. However, previously kingpin engineers and project managers communicated with and related to human resources at corporate and divisional levels through paperwork. Interviews with HR managers indicated that this relationship was usually handled in a crisis management, 'I want it yesterday', style. In order to reform this pattern of relationships the management development and technical excellence programmes focused on the communication and competitive benefits of 'project task forces' (PTFs).

The PTF programme was introduced in a week-long training session for project managers, corporate HR staff and engineering design, construction and site staff. The intention was to bring a senior member of each division into the planning stage of any

FIGURE 1 Exbeck structure and competitive strategy

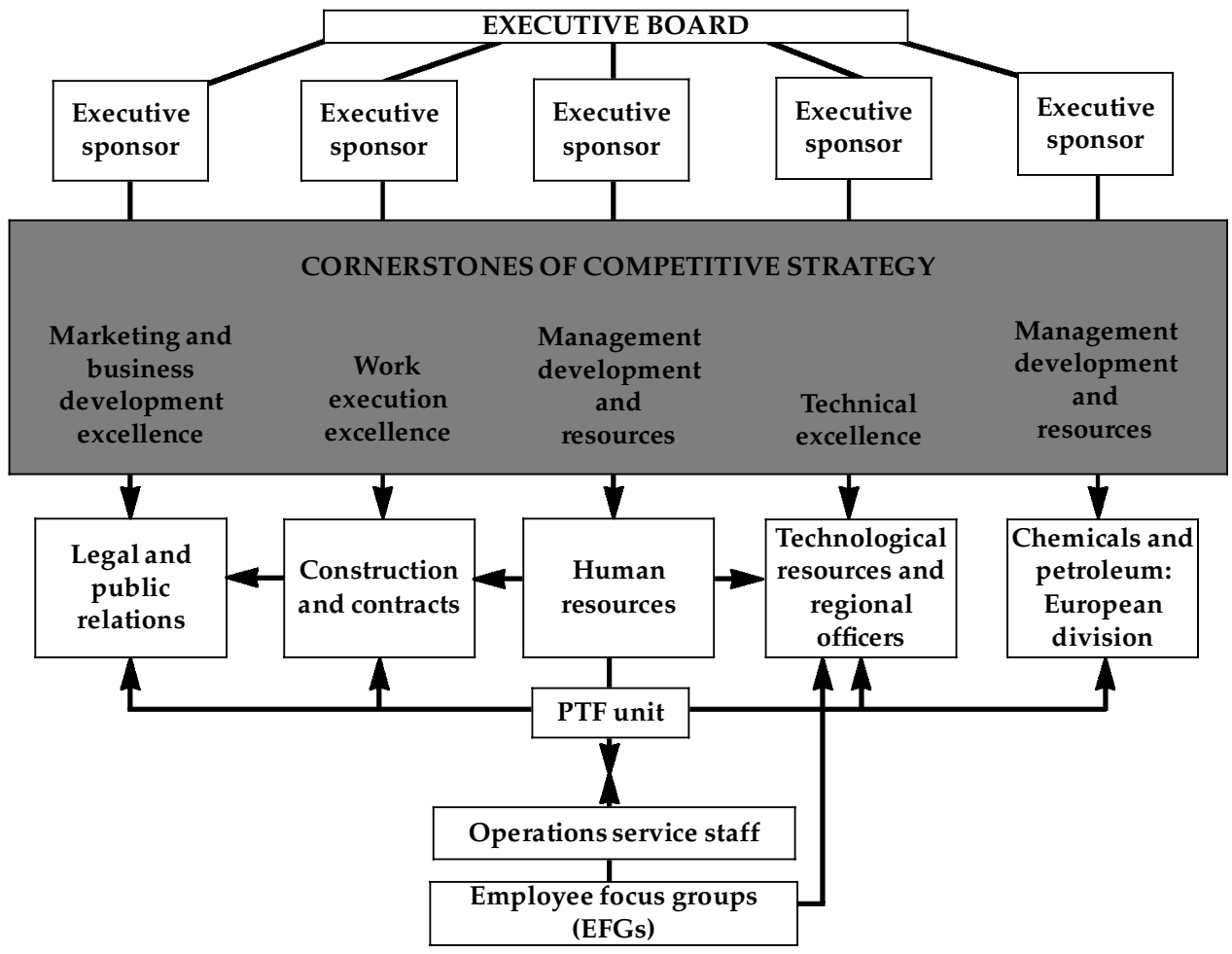


particular tender which was usually won or bid for by the construction and contracts division. Under the system the construction and contracts project manager prepares a briefing document on the technical and process requirement of a project and provides a forecasting plan for HR needs over the length of the project. PTF members from the other four divisions then formulate their own costed plans for contracts, human resources, process licenses etc. These are then fed back to the project manager in order for the bid to be accurately costed. If the tender is subsequently won, the PTF 'goes live' with each division organising the secondment of necessary staff. The HR function identifies staff training and development needs and works with the project manager to ensure accurate HR scheduling to help contain costs to tender specifications.

Initially there was considerable resistance from engineering and process technology staff who, while accepting the inclusion of people from the HR function, did not consider them 'up to the job' of live operations. Equally, although PTFs are autonomous groups for project management, they remain under the executive control of the construction and contracts group, whereas 'functional task' ownership rests with the appropriate task force division. For example, human resources would staff a PTF on the basis of internal contracting, whereas previously project and site engineers requested named individuals. A one to three-month reporting period is targeted, depending on the size and complexity of the project, for initial formulation of PTF costing and resource requirements. Figure 2 illustrates how a PTF operates.

The PTF system challenged the internal hierarchy of staff at Exbeck but gave the firm a more accurate business planning portfolio. Equally, PTFs gave Exbeck more accurate costings for labour requirements at the pre-project stage; this was seen as a major benefit in that inaccurate internal costings and subsequent cost overruns could easily be identified.

\section{$3 \mathrm{HRM}$ as a full business partner}

The corporate HR function was charged with responsibility for the management development programme and monitoring corporate and divisional coherence in the contemporary PTF framework for management practice. The renewed business strategy at Exbeck clearly identified the need for a developmental approach to the workforce; this was summarised as ensuring delivered value in a PTF to demonstrate quality tenders and quality added value to the client. For the executive sponsor of the HR function this entailed four tasks. The first was to position HR staff and services within PTFs in order to identify and cost the human resource needs of the business at an early pre-planning stage. The second was to demonstrate the benefits of an upstream competitive and HR strategy to line managers in PTFs; thirdly, to show corporate HR staff that their presence within a PTF system was valued and taken seriously; and, lastly, to demonstrate 'empirically' to clerical and administration support staff throughout the organisation that non-engineering staff were valued in the same way as technical and engineering staff.

The head of human resources, its executive sponsor and the company president expressly used the word 'empirically'. In interviews they argued that Exbeck could not confine its development programme to managers alone and here the head of human resources argued this was precisely the problem with 'designer HRM'; for the employees it was merely rhetoric. To avoid this the benefits of the PTF system had to be reproduced at lower levels in the firm; administrative and clerical staff had to be involved with and participate in the PTF system. This issue illustrated considerable forethought, to the extent that the head of human resources was not thinking about 'transformation', but how and why the PTF system might fail.

Both the monitoring and recruitment measures were pushed through in order to persuade engineers and project leaders to take the HR function seriously. However, it was 


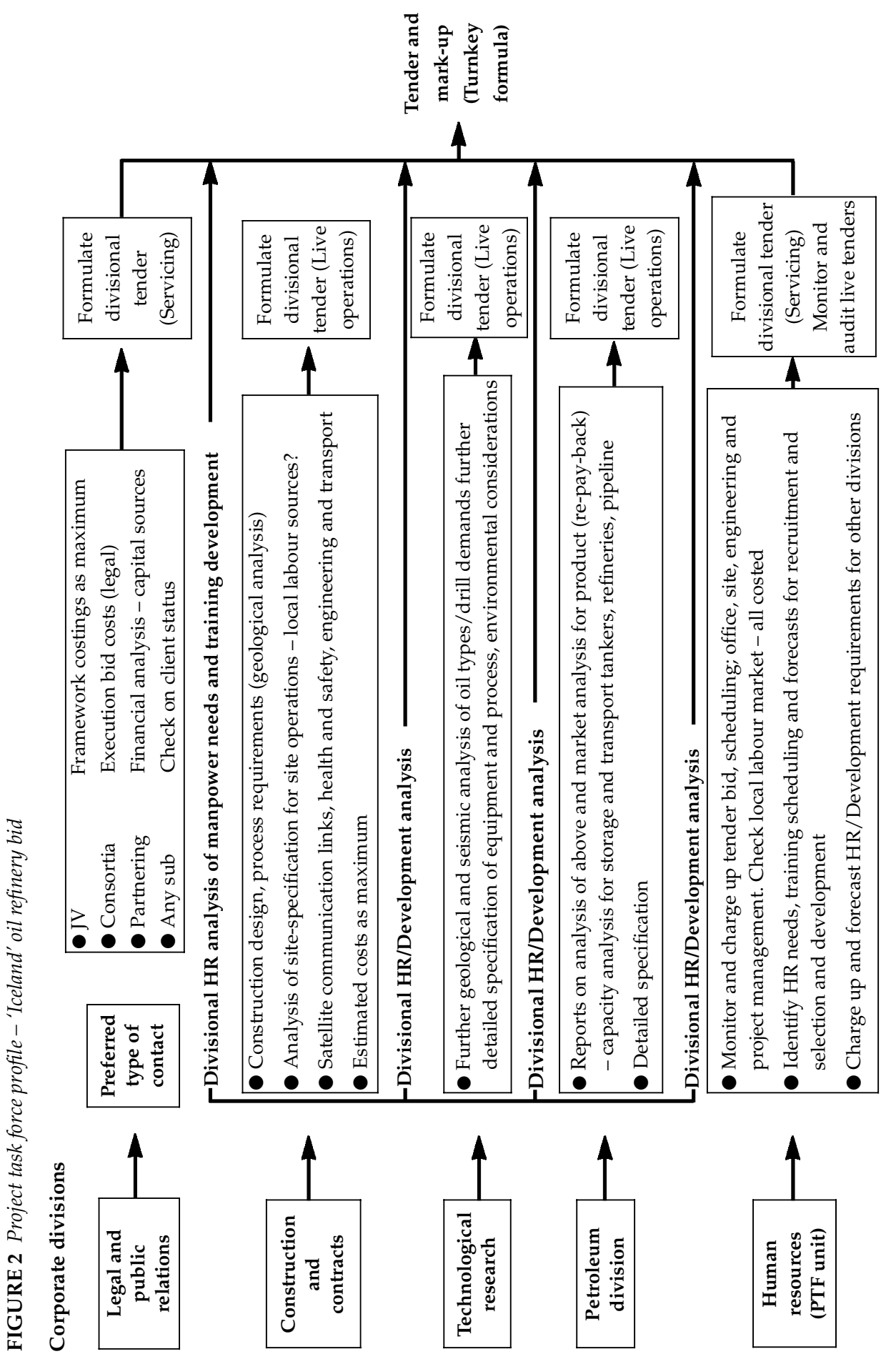


made clear to the head of human resources that their job was not to exercise 'fanciful' control; rather, human resources at corporate level were briefed to use their position to improve information and communication flows between themselves and project groups, in order that the PTF system could operate effectively and to budget. The emphasis was on human resource management, not necessarily human resources, managing the line.

To raise the internal profile of human resources to the status of a full business partner, the executive sponsor and the head of human resources fleshed out the HR agent for change programme by focusing on three constituencies for corporate level operations - HR agencies, agency targets and competitive benefits for Exbeck (see Figure 3 overleaf).

There were three agencies where intervening action was deemed necessary for the HR function to establish itself as a full business partner. The first was management practice which was specifically targeted at project management in PTFs. The second was the overall HR programme of initiatives which were directed to Exbeck's business needs. These centred on the training and development programme for line managers, HR managers - who were to be positioned in the human resources PTF unit - and line staff who had to operate within the new PTF system. The third area of active operations was the maintenance of employee services, focusing on improving employee relations, compensation and benefits for non engineering and project staff.

The training and development programme was targeted on two levels. The first group consisted of line managers in PTFs, including the human resources PTF unit. The thrust of PTF training and development relates to Figure 2, where the PTF system is sketched out. The corporate HR function briefs and trains up the five corporate divisions in how PTFs are designed to operate, in particular their internal reporting procedures. For the HR PTF unit this involved attendance at day schools on project management in other corporate divisions, whereas members of other corporate divisions had to attend HRM day schools. The object was to make members of each corporate division think beyond their own function. After attending four day schools beyond their specialist area, PTF members were asked to work on a dummy bid, 'Iceland refinery'. Here, members had to complete a learning log summarising their contribution to the management of the project and how it was improved as a result of the PTF system - in particular how the inclusion of human resources people at the preliminary stage had challenged their way of thinking.

The second target group for the training and development programme covered administrative and clerical staff. In order to demonstrate its commitment to an upstream competitive strategy, Exbeck initiated an employee attitude survey to assess what employees felt was necessary at 'ground level' for them to participate in this innovation. The results were not initially encouraging. (The author was allowed to examine the survey material and conduct a small 'independent' survey in the corporate headquarters and the London office in order to verify the company survey; the results of this second survey were consistent with those of the firm.)

The main findings of the survey were threefold. First, clerical and administrative staff felt that they had no stake in the company and were continually 'dumped on' by engineers and project managers who did not know how to take care of paperwork or show any interest in the internal reporting systems. Secondly, support staff, including human resources, found it difficult to maintain commitment to and identification with particular projects. Equally, because staff were not seconded to work on particular projects, it became difficult to trace problems or find files when the project manager 'demanded' to know what had happened to particular requisitions - often staff had moved to another project or in some cases left the organisation. Thirdly, the majority of the support staff felt it was likely that they would lose 

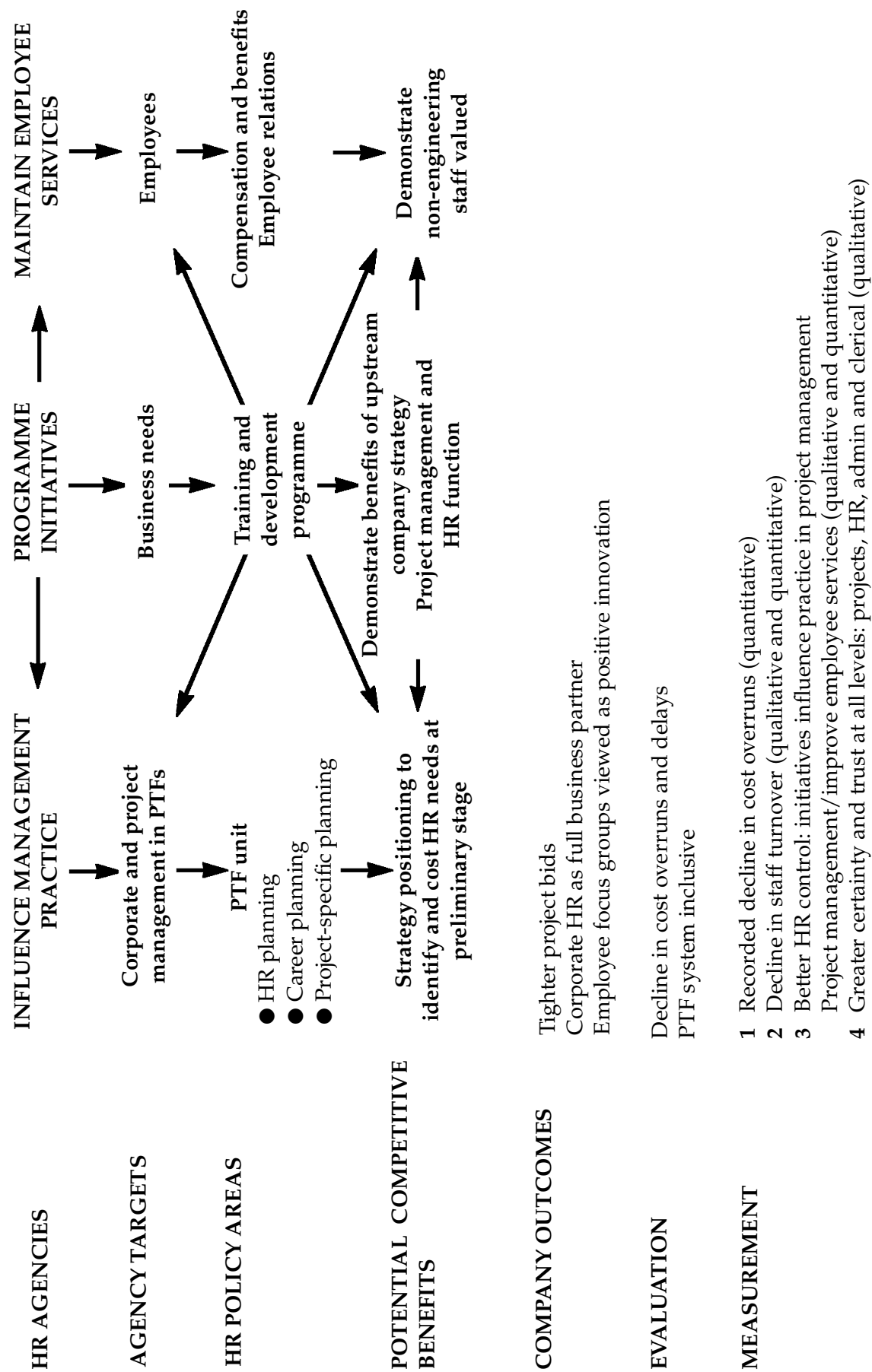
their job as a result of the renewed business strategy; therefore they felt no need to commit to or be interested in what was happening. As a response to this the head of human resources sought to mirror the PTF approach at the operational level by formulating a system of employee focus groups for clerical and administrative support staff. This was designed to improve employee morale and trust in the wake of the attitude survey and disgruntled soundings in employee review and appraisal sessions.

The system of focus groups operates across divisions, whereby administrative and clerical staff working on a particular PTF have the opportunity to liaise with staff in other divisions. Equally, employee focus groups meet periodically to discuss how a project is going and share problems they have experienced with PTF staff. PTFs have a defined roll of members, therefore focus group staff are able to identify particular members they need to see. Since 1996 focus groups and PTFs have been networked and now most communication operates via e-mail. Yet, in the initial stages of a PTF, personal contact and visits between members and focus group members remains the norm. After each periodic focus group meeting a report is produced; these are picked up by the relevant task force, with any defective or incomplete requisitions sent back to the originator in the PTF. Equally, employee focus groups report to the HR function on how effectively a PTF is conducting its internal business in terms of its paperwork facilitating speedy turnarounds.

As a second response Exbeck introduced an 18-day working month; all support staff were given a paid day off every two weeks. A 37-hour working week was introduced, and as part of the employee task force system support staff were encouraged, if the situation was urgent, to act independently in sourcing service requests. For example, if a requisition was marked urgent but was not correctly specified, costed or clearly signed off, support staff were encouraged to use their experience and discretion. If such action was deemed incorrect by the PTF, but undertaken in the absence of essential information, the PTF would have the 'worked time' added to their budget and bid costs. At the initial stage engineers and project managers did not take this seriously, but after about nine months they began to realise the implications of failure to operate in a collegiate manner:

I cost my PTF $\$ 1$ million because I didn't specify a particular process license request, and when I checked the requisition and found it was the wrong process our support staff (in contracts and construction) informed me that the situation could not be reversed and we had to spend another $\$ 500,000$ on the correct process license. What was ridiculous was that all the correct details were in the tender. If I'd attached a file copy of the tender to an e-mail and not written 'process as usual', the support staff would have found the correct specification already costed and drafted. A million dollars sounds a lot but in the context of a project tendered at $\$ 300$ million it's not. But I had to work hard to get my section to meet the mark-up target.

The interviewee added that in the old days he could have 'lost' such a small cost error, but now it is all clearly recorded. He added that he couldn't even blame the 'bozos in personnel'. When asked what action he took as a result of this encounter he replied:

It's not like the old days. They really mean business with this PTF and employee focus group stuff; you can easily get a reputation as a waster and you don't want that unless you want to spend your next project management secondment on the Alaskan pipeline.

A year after the introduction of employee focus groups support staff appeared more confident and valued by the engineers and project managers:

I've worked here for six years and, until last year, I never even saw an engineer and I don't know any socially. Now, if they waste something, they come down here and ask us if there is anything we can do to sort it out and they actually listen to you. 
In summary, by incorporating support staff through employee focus groups, Exbeck sought to demonstrate to the kingpins that they had to change the way they conducted themselves. 'Casual' crisis management and poor paperwork were no longer acceptable, particularly once a tender had gone live.

In many respects the work of the HR function remained the same, but its strategic profile was much higher. Many kingpins did not like this but gradually recognised its benefits. HR planning at the tender stage became human resourcing, training and development or recruitment at the stage when a tender went live. Previously, labour and process license costings were estimates based on similar projects; now they were individual, more accurate and helped preclude the norm of crisis management in the deployment of human resources.

The embedded competitive framework within EPPC clearly influenced Exbeck's management in their choice of business and HR strategies. This point is not necessarily new (see Capelli, 1985; Kochan et al, 1984; Marchington and Parker, 1990 for a theoretically and empirically-based discussion). However, the institutional apparatus and competitive conditions found in this study are unique; for example, the competitive framework of project tendering is long established and is unlikely to change. Further, Exbeck could not respond to its business problems of the early 1990s by seeking to intensify its competitive profile on the basis of 'measured productivity improvements'; that is, headcount reductions (more popularly termed downsizing) and more flexibility.

The product market and market conditions were not necessarily deterministic but highly influential. In terms of Cappelli and McKersie's (1987) work on management strategies in intensified competitive conditions, Exbeck rejected an asset management approach based on asset stripping and downsizing in favour of the described approach of value added and cost containment. Value was added and costs contained between divisions by the PTF system, where the corporate HR function operated as a task force producer. This approach bears out Capelli and McKersie's argument that competition based on quality and value is designed to sustain the profitability of existing business or, in Exbeck's case, to improve their marginal efficiency within the embedded nature of competition in EPPC.

The quality and value added in PTFs was supported by a management development programme that was designed to secure corporate coherence across the five operating divisions and internal operating coherence within divisions through the deployment of employee focus groups. The measures of coherence were designed to secure more accurate project bids and forecasts for HR needs.

The financial benefits of the change process are difficult to determine but the chief executive made it clear that some efforts had to be made here to justify the promotion of human resources to the status of a full divisional business partner. As Figure 3 illustrates, the potential competitive benefits of HR as a full business partner are measured qualitatively and quantitatively and evaluated against competitive outcomes. It was decided to examine aspects of the financial and project performance for 1991 and compare it with $1992{ }^{3}$.

\section{FINANCIAL PERFORMANCE}

In order to undertake this aspect of the project, quantitative data was examined from published company accounts. In addition project data for the test cases was examined in Exbeck's corporate HQ and its London office from where the particular projects were controlled. Further, several interviews with project managers and HR managers were undertaken. The interviews with HR staff were particularly valuable because it was possible to visualise their situation before and after the introduction of the human resources PTF unit. 
The average value of an Exbeck project is $\$ 85$ million. Currently, project management mark-ups are in the order of 10 per cent. In the operating year 1992 Exbeck booked new work to the value of $\$ 7.2$ billion; this was costed and bid for under the PTF system.

To evaluate the financial contribution of the management and staff development programme and the PTF system two courses of action were undertaken. First, for two projects that started prior to the PTF system, the cost overrun was internally traced and diagnosed (the audit trace system is described in Appendix 2). Secondly, two PTF-managed projects were examined to evaluate any reduction in cost overrun in an attempt to estimate the monetary value of including the human resources PTF unit in project pre-planning, bid tender formulation and subsequent live operations.

The four projects under consideration are relatively similar in scale and cost, and represent the average for an Exbeck project. The construction and testing period for the projects was three years, so the two 1991 starts were completed in 1994 whereas the 1992 starts were completed in 1995. Both 1991 starts came in with a 5 per cent overrun on the turnkey bid, ie $\$ 4.2$ million or an annual average of $\$ 1.4$ million. In contrast the PTF starts came in with turnkey overruns of around $\$ 1$ million each or an annual average of $\$ 333,000$.

The internal audit trace revealed several sources of cost overrun on the 1991 starts: site contractor failures under subsequent litigation, adverse weather conditions that precluded construction and testing, failures of process technologies and, in their second and third years, both 1991 starts were behind schedule due to project management failures. The latter included a failure to book design engineers in advance and problems associated with process failures that were traced back to incorrect license requisitions by Exbeck, which in turn held up construction by the process technologists. Further, Exbeck could not 'find' enough design, construction and project engineers who were available and trained up for particular aspects of the projects. This failure triggered the crisis process of drafting in staff from other projects and, in one case, headhunting a named individual from another corporation.

The audit trace process indicated that half of the 1991 start overruns were attributable to direct and indirect HR failures, in particular a failure of HR project pre-planning and associated training. In addition, the absence of the PTF system and employee focus groups meant that errors or queries on requisition claims were not followed up or corrected. Not all of these led to cost overruns but several did, with some creating very large additions to costs.

For the projects started under the PTF system, relatively little of the annual cost overruns were attributable to HR failures; there were still some problems with the accuracy of process license requests, but the system of employee focus groups picked this up. Here some potentially costly errors were rescued when administrative staff queried the paperwork with the appropriate PTF leaders. In summary, the internal audit trace indicated that on the two 1992 starts the promotion of the HR function into the PTF system saved Exbeck in the region of $\$ 1.8$ million per project ( 2 per cent of the tender price) in terms of reduced cost overruns.

The overall cost of the PTF system, the management and staff development programme was around $\$ 4$ million dollars. This figure includes the management consultancy fee and extra provision for employer pension contributions, health care plans in the US and corporate BUPA options in the UK, but excludes extra and higher wage payments. In quantitative terms it is clear that the centralised strategic approach to HR planning and development would pay for itself in under two years.

In qualitative terms employee morale and motivation were significantly improved. All groups, in particular design and project engineering staff, reported that the development programme had significantly improved their awareness of the benefits of cooperative and collegiate working with other employees within and beyond the immediate PTF. Secondly, 
and related to the first point, quality in work improved significantly. This was especially the case in administrative and clerical fields which supported a PTF. Staff reported that, by being encouraged to take independent action (but being aware of project objectives), this enabled them to anticipate potential problems while following through work assignments in the employee focus group system. That is, staff felt that they now had a mechanism, if necessary, to query, audit and check what they were being asked to do which was reported back on very quickly. Thus the transmission mechanism of employee focus groups fed into PTFs very effectively.

Both of the above points were improved because of a third factor. The PTF system and the overall development programmes illustrated the propriety of accurate costing, meeting budgets and work schedules. In some cases employee focus groups queried requested work and made alternative suggestions for lower cost works. Prior to the PTF system administrative or clerical staff in any division never queried the requests of a kingpin, even if they thought it was wrong. The accounts director and the head of human resources introduced a management services guideline document on cost overruns which had to be logged if the actual cost of labour, materials or licenses rose above the budgeted bid price. These were then reviewed by the relevant project manager. As a measure of financial discipline this innovation was mainly used against kingpins. Clerical and support staff saw this as a positive move that further improved their morale, as previously they were usually blamed because errors were not always traced back to source and, even if they were, some project managers would write them off rather than challenge a fellow kingpin.

Lastly, Exbeck re-worked its performance review criteria and internal promotion and merit pay systems. The emphasis was redirected to initiative, dependability, working with others, effective internal communication and first-time quality as factors which contributed directly to standard performance measurement categories such as job knowledge and productivity.

\section{CONCLUSIONS}

Practitioner bodies - the IPD in the UK and the Society for Human Resource Management in the US - are troubled by the observed finding that the HR profession is undervalued at operational levels and unable to establish and justify a position at corporate level. Further, research evidence (Storey, 1992; Purcell and Alhstrand, 1994; Sisson, 1994; Kochan and Dyer, 1995) indicates that the function is struggling to assert itself as a strategic actor, that implementation of HR initiatives is piecemeal and that line managers are more active and influential in this area that HR professionals. Moreover, the arguments of practitioner bodies for a strong HR function are easily made (IPD, 1995), but must be empirically proven by practitioners and scholars if corporate policy makers are to consider the potential contribution and significance of human resources to 'bottom line' financial performance.

The evidence from this case raises wider and more contentious issues for practitioners and scholars: What is best practice? Are firms such as Exbeck ahead of the practitioner and academic communities? Exbeck established a positive link between a strategically repositioned corporate HR function and its financial performance. The sample evidence derived from four recent projects suggests that the previously peripheral role of the function in project management did impair financial performance. In contrast to this, full business partnership led to a quantifiable improvement in financial performance.

In Exbeck's case organisational restructuring has led to a centralised, more strategic, HR function where the quantifiable impact of the changes made are measurable and significant. The wider implications of this study and its contribution to practitioner and academic debate are threefold. First, a consideration of the size and financial magnitude of operations 
is instructive in assessing the role of human resources within a firm. The cost of a well developed and strategically integrated HR function can be usefully positioned against a firm's operations costs. This may help identify the potential for qualitative and quantitative improvements in performance that derive from a more engaged deployment of human resources, particularly at corporate level.

Secondly, corporate human resources staffed by qualified practitioners can operate as a centralised strategic business partner and maintain integrity with line management if competitive conditions in a firm's product market encourage senior executives to commit to this.

Thirdly, practitioners and scholars must recognise that even a centralised, strategically integrated and interventionary HR function has, in economic terms, a marginal impact on quantitative efficiency and qualitative improvement in the deployment of staff. The key variables in this relationship are the cost of strategic integration and the operational returns derived from integration. In Exbeck's case the quantifiable improvements in project management vastly outweigh the qualitative and quantitative costs associated with the process of internal restructuring that resulted in a more strategic role for human resources. In the circumstances of this case the absence of a centralised and interventionary corporate human resource function was not sustainable.

\section{Acknowledgements}

The author would like to thank HRMJ's referee and De Montfort colleagues Buchanan, Claydon, Colling and Storey for instructive comments on an earlier draft.

\section{Notes}

1 Contacts for this study were established as a result of work on the ESRC programme, 'The competitiveness of British industry' (contract no. W. F. 20250031). Subsequent work and the cost of international travel was funded by a grant from Leicester Business School. Because of the highly competitive nature of business in EPPC - in particular the bidding process - it has not been possible to use the real name of the case firm.

2 For example, European Chemical News, the Financial Times or Hydrocarbon Processing.

3 This information is highly sensitive and has been disguised for competitive reasons.

\section{REFERENCES}

Ball, D. 1985. Process Plant Contracting Worldwide, London: Financial Times Business Information.

Ball, D., Clark, I., Robertson, H. and Pearson, A. 1992. 'Strategic alliances in process plant contracting'. Paper presented at the Third Management of Technology Conference: The Key to Global Competitiveness: Proceedings of the Third International Conference on the Management of Technology, Volume 1. The University of Miami.

Capelli, P. 1985. 'Competitive pressures and labour relations in the airline industry'. Industrial Relations, Vol. 22, no. 3, 316-338.

Capelli, P. and McKersie, R. 1987. 'Management strategy and the redesign of work rules'. The Journal of Management Studies, Vol. 24, no. 5, 441-462.

Clark, I. and Ball, D. 1991. 'Transaction cost economics applied? Consortia within Engineering Process Plant Contracting'. The International Review of Applied Economics. Vol. 5, no. 3, 341-357.

Guest, D. 1990. 'Human resource management and the American dream'. The Journal of Management Studies, Vol. 27, no. 4, 378-397. 
Institute of Personnel and Development. 1995. 'People make a difference'. IPD Position Paper. London: IPD.

Kochan, T. and Dyer, L. 1995. 'HRM: an American view' in Human Resource Management: A Critical Text. J. Storey (ed). London: Routledge.

Kochan, T., McKersie, R. and Capelli, P. 1984. 'Strategic choice and industrial relations theory'. Industrial Relations, Vol. 23, no.1, 16-39.

Legge, K. 1995. Human Resource Management: Rhetoric and Realities, London: Macmillan.

Marchington, M. and Parker, P. 1990. Changing Patterns of Employee Relations, Brighton: Harvester Wheatsheaf.

Purcell, J. and Alhstrand, B. 1994. Human Resource Management in the Multi Divisional Firm, Oxford: Oxford University Press.

Sisson, K. 1994. 'Personnel management: paradigms, practice and prospects' in Personnel Management. K. Sisson (ed). Oxford: Blackwell.

Storey, J. 1992. Developments in the Management of Human Resources, Oxford: Blackwell.

\section{Appendix 1}

Formal interviews were conducted with the corporate head of human resources and the HR policy leaders in each section at this level. Over the course of the project follow-up interviews were held after significant organisational innovations such as the PTF system. The author was able to attend and participate in strategy meetings and briefing sessions. From 1994 Exbeck held some strategy meetings in human resources via video conferences; in these cases the author was able to 'attend' and 'participate' from the London divisional office. The chief executive was interviewed on the emergent system and the use of executive sponsors.

Exbeck made all internal HR documents available. In addition the author was able to attend some employee appraisal and performance rankings for individual employees and employee focus groups. In both cases independent notes were taken which were used in individual interviews between employees and the author.

The attitude survey examined employee views on the division between kingpins and administrative and clerical staff, other weaknesses in work organisation and impediments to meeting performance targets under the kingpin system of project management.

Interviews with project managers posed more of a problem. Initially the author was 'identified' as a management consultant. Once this problem was overcome resistance subsided. However, throughout the project the attitudes of project managers to the PTF system only moved from one of distrust to reluctant acceptance.

\section{Appendix 2}

Audit tracing was conducted in the construction and contracts division at corporate $\mathrm{HQ}$ and the London divisional office. The process involved checking original tender bids against work-off costs and project profits. The system was accurate but blunt; for example, in some cases it was not possible to find data, so original tender bids were used in calculations, and thus the trace may have underestimated cost overruns.

Data on labour costs, training, HR planning and scheduling and recruitment was traced by testing final costs against book costs. The same process was used for materials, plant and other requisitions. Apportioning responsibility for overruns was contentious and in interviews which included human resources and project managers there were irreconcilable differences. 